\title{
Assessment of Prognostic Value of "Neutrophil to Lymphocyte Ratio" and "Prognostic Nutritional Index" as a Sytemic Inflammatory Marker in Non-small Cell Lung Cancer
}

\author{
Fahriye Tugba Kos ${ }^{1 *}$, Cemil Hocazade ${ }^{2}$, Mehmet Kos $^{3}$, Dogan Uncu ${ }^{2}$, Esra \\ Karakas $^{4}$, Mutlu Dogan², Hikmet Gulsen Uncu ${ }^{5}$, Nuriye Ozdemir ${ }^{2}$, Nurullah \\ Zengin $^{2}$
}

\begin{abstract}
Background: Systemic inflammatory response was shown to play an important role in development and progression of many cancer types and different inflammation-based indices were used for determining prognosis. We aimed to investigate the prognostic effects of neutrophil to lymphocyte ratio (NLR) and prognostic nutritional index (PNI) in patients with non-small cell lung cancer (NSCLC). Materials and Methods: NSCLC patients diagnosed in our institution were retrospectively reviewed. Demographic and clinicopathologic characteristics were recorded. NLR and PNI was calculated before the application of any treatment. Results: A total of 138 patients were included in the study. Patients were divided into two groups according to NLR $(<3.24$ or $\geq 3.24)$ and PNI (<49.5 or $\geq 49.5$ ). While median overall survival was 37.0 (95\% CI 17.5-56.5) months in the group with low NLR, it was calculated as $10.0(95 \%$ CI 5.0-15.0) months in the group with high NLR $(p<0.0001)$. While median overall survival was 7.0 (95\% CI 3.5-10.5) months in the group with low PNI, it was calculated as 33.0 (95\% CI 15.5-50.4) months in the group with high PNI $(\mathbf{p}<0.0001)$. Stage, NLR and PNI levels were evaluated as independent risk factors for overall survival for all patients in multivariate analysis $(p<0.0001, p=0.04$ and p $<0.001$, respectively). Conclusions: NLR $(\geq 3.24)$ and PNI $(<49.5)$ at diagnosis is an independent marker of poor outcome in patients with NSCLC. NLR and PNI is an easily measured, reproducible prognostic tests that could be considered in NSCLC patients.
\end{abstract}

Keywords: Neutrophil - lymphocyte - prognostic nutritional index - lung cancer - prognosis

Asian Pac J Cancer Prev, 16 (9), 3997-4002

\section{Introduction}

In recent years, systemic inflammatory response developing against cancer cells was shown to play an important role in development and progression of many cancer types (Sun et al., 2014). The inflammation in tumor microenvironment is characterized by presence of host leucocytes both in stroma and tumor site. T-cell population is predominant in the tumor microenvironment. It has been reported that mainly IL-4 and 5 cytokines produced from Tumour-infiltrating T cells (TIL) in some tumors including lung cancer may contribute to cancer growth, spreading and malignancy-induced immunosuppression (Balkwill and Mantovani, 2001).

Indices containing various inflammatory parameters were used for determining prognosis in cancer patients. Of them, prognostic nutritional index (PNI) was reported to be an effective marker for predicting surgical risk in particularly gastrointestinal tumors (Onodera et al., 1984).
Following studies also showed that low PNI values is a predictive factor for poor survival in gastrointestinal system cancers (Nozoe et al., 2002; Pinato et al., 2012; Wang et al., 2012; Mohri et al., 2013). Neutrophil to Lymphocyte Ratio (NLR), another systemic inflammatory index was evaluated in many cancer types and high NLR values were found to be associated with poor prognosis (Kwon et al., 2012; Wang et al., 2012; Xu et al., 2014).

Lung cancer has the greatest mortality among cancers despite all preventive and therapeutic approaches (Siegel et al., 2013). Improving survival in lung cancer is a major challenge for modern oncology considering that 5-year survival remains $<15 \%$, across all stages of disease and with $<7 \%$ of patients alive 10 years after diagnosis (Crinò et al., 2010). Therefore determining high risk patients using prognostic parameters is important in this cancer type. Advantages of using laboratory parameters as a prognostic criteria are their being easily available, reproducible and inexpensive. There are limited number

${ }^{1}$ Department of Medical Oncology, ${ }^{3}$ Department of Internal Medicine, Faculty of Medicine, Duzce University, Duzce, ${ }^{2}$ Department of Medical Oncology, ${ }^{4}$ Department of Internal Medicine, Ankara Numune Education and Research Hospital, ${ }^{5}$ Turkish Drug \& Medical Device Institution, Ankara,Turkey*For correspondence: tugbasan@yahoo.com 
of studies evaluating the prognostic importance of NLR as a systemic inflammation marker in patients with NSCLC (Sarraf et al., 2009; Tomita et al., 2011; Cedrés et al., 2012; Yao et al., 2013; Kacan et al., 2014). However, to the best of our knowledge, no studies are available in literature investigating the value of PNI as a prognostic factor in patients with NSCLC. Therefore, we aimed to investigate the association between NLR and PNI values and overall survival in patients with NSCLC.

\section{Materials and Methods}

The patients with a confirmed diagnosis of NSCLC histopathologically followed-up at our in medical oncology clinic between May 2005-July 2011 were included. The clinicopathologic characteristics, laboratory data, treatment data of the patients have been reached by screening the hospital automation system and file archive system retrospectively. All patients were classified as stage I to stage IV, according to the guidelines of the tumor-node-metastasis (TNM) staging system of the Union for International Cancer Control (7th edition). The neutrophile, lymphocyte and albumin levels of patients before received any treatment according to the stage were recorded. NLR was defined as the absolute neutrophile count divided by the absolute lymphocyte count. PNI was then calculated with the following formula: $10 \mathrm{x}$ serum albumin value $(\mathrm{g} / \mathrm{dl})+0.005 \mathrm{x}$ peripheral lymphocyte count (per mm3) (Migita et al., 2013). The patients whose file information was missing or inaccessible, the patients with signs of inflammation and those with comorbid disease which may affect the neutrophile and lymphocyte counts, and the patients who were using drugs which may lead changes in these values were excluded. Final clinical condition of the patients was learned from hospital records of by phone calls.

\section{Statistical analysis}

Medians, and frequencies were calculated for patient demographics. Chi-square or Fisher exact tests were used for comparative analysis of categoric data. The duration of overall survival (OS) was calculated from date of pathologic diagnosis and the death or until the date of the last follow-up visit. A receiver operator characteristic (ROC) curve was constructed to reveal an association between NLR or PNI and survival. Overall survival was estimated using the Kaplan-Meier method and the log-rank test was used for comparison of outcomes. A Cox regression model was used to analyze independent prognostic risk factors. A p-value $<0.05$ was considered statistically significant. All statistical analyses were performed using the Statistical Package for the Social Sciences software program version 16.0 (SPSS Inc., Chicago, IL, USA).

\section{Results}

One hundred thirty-eight patients were included in the study whose all parameters could be achieved. The median age of patients was 57.0 years (range :26-83). One hundred twenty-four patients $(89.9 \%)$ were men and $14(10.1 \%)$ of them were women. Fifty (36.2\%) patients had metastasis at diagnosis. Bone (15\%) and brain (12\%) metastase were the most common metastatic sites. Adenocarcinoma $(n=57,41.3 \%)$ was the most frequent histological subtype.

Receiver operating characteristic (ROC) curves for overall survival prediction were plotted to verify the optimum cut-off point for NLR. The area under the ROC curve was 0.683 [95\% confidence interval (CI):0.5730.793 ] and according to the ROC curve, the best cut-off value of NLR was 3.24, with a sensitivity of $69.6 \%$ and a specificity of $69.2 \%$. Patients were then divided into two groups according to NLR: 51 (36.9\%) patients with NLR $<3.24$ and $87(63.1 \%$ ) patients with NLR $\geq 3.24$. Median PNI was used to divide patients into the low PNI group $(<49.5)$ and high PNI group $(\geq 49.5)$. it was sixty-nine patients $(50 \%)$ in both groups.

When the patients in low NLR group and high NLR group were compared, their ECOG performance scores were found to be better and their surgical procedure rates were greater ( $p=0.007, p=0.007$, respectively). When PNI groups were compared, patients with low PNI scores were

Table 1. General Characteristics of Patients According to NLR Groups and PNI Groups

\begin{tabular}{|c|c|c|c|c|c|c|c|}
\hline \multicolumn{2}{|c|}{ Characteristics } & $\begin{array}{c}\text { NLR }<3.24 \\
(\mathrm{n}=51) \\
\mathrm{n}(\%)\end{array}$ & $\begin{array}{c}\text { NLR } \geq 3.24 \\
(\mathrm{n}=87) \\
\mathrm{n}(\%)\end{array}$ & $\mathrm{p}$ & $\begin{array}{c}\mathrm{PNI}<49.5 \\
(\mathrm{n}=69) \\
\mathrm{n}(\%)\end{array}$ & $\begin{array}{c}\mathrm{PNI} \geq 49.5 \\
(\mathrm{n}=69) \\
\mathrm{n}(\%)\end{array}$ & $\mathrm{p}$ \\
\hline \multirow[t]{2}{*}{ Age* } & $<57$ & $23(45.1)$ & $42(48.3)$ & 0.73 & $25(36.2)$ & $40(58.0)$ & 0.02 \\
\hline & $\geq 57$ & $28(54.9)$ & $45(51.7)$ & & $44(63.8)$ & $29(42.0)$ & \\
\hline \multirow[t]{2}{*}{ Gender } & Female & $8(15.7)$ & 6(6.9) & 0.14 & $6 \quad(8.7)$ & 8 (11.6) & 0.78 \\
\hline & Male & $43(84.3)$ & $81(93.1)$ & & $63(91.3)$ & $61(88.4)$ & \\
\hline \multirow[t]{2}{*}{ ECOG } & $0-1$ & $38(74.5)$ & $44(50.6)$ & 0.007 & $31(44.9)$ & $51(73.9)$ & 0.001 \\
\hline & $2-3$ & $13(25.5)$ & $43(49.4)$ & & $38(55.1)$ & $18(26.1)$ & \\
\hline \multirow[t]{2}{*}{ Stage } & I-III & $37(72.5)$ & $51(58.6)$ & 0.14 & $38(55.1)$ & $50(72.5)$ & 0.05 \\
\hline & IV & $14(27.5)$ & $36(41.4)$ & & $31(44.9)$ & $19(27.5)$ & \\
\hline \multirow[t]{3}{*}{ Histology } & Adenocarcinoma & $20(39.2)$ & $37(42.5)$ & 0.66 & $26(37.7)$ & $31(44.9)$ & 0.23 \\
\hline & Squamous cell & $22(43.1)$ & $31(35.6)$ & & $25(36.2)$ & $28(40.6)$ & \\
\hline & Other** & 9 (17.6) & $19(21.8)$ & & $18(26.1)$ & $10(14.5)$ & \\
\hline \multirow[t]{4}{*}{ Treatment } & Surgery & $28(54.9)$ & $27(31.0)$ & 0.007 & $17(24.6)$ & $38(55.1)$ & $<0.0001$ \\
\hline & Radiation & $15(29.4)$ & $18(20.7)$ & 0.30 & $15(21.7)$ & $18(26.1)$ & 0.69 \\
\hline & Chemoradiation & 9 (17.6) & 11 (12.6) & 0.46 & $9(13.0)$ & $11(15.9)$ & 0.81 \\
\hline & Chemotherapy & $42(82.4)$ & $71(81.6)$ & 0.91 & $56(81.2)$ & 57 (82.6) & 0.82 \\
\hline
\end{tabular}

* The patients were separated into two groups according to median value of age; **Adenosquamous, large cell, mixed, unknown subtypes, etc 
seen to be older than the patients with high PNI scores, their ECOG performance status was poorer, they were in advanced stage and surgical procedure application rates were lower $(\mathrm{p}=0.02, \mathrm{p}=0.001, \mathrm{p}=0.05$ and $\mathrm{p}<0.0001)$ (Table 1).
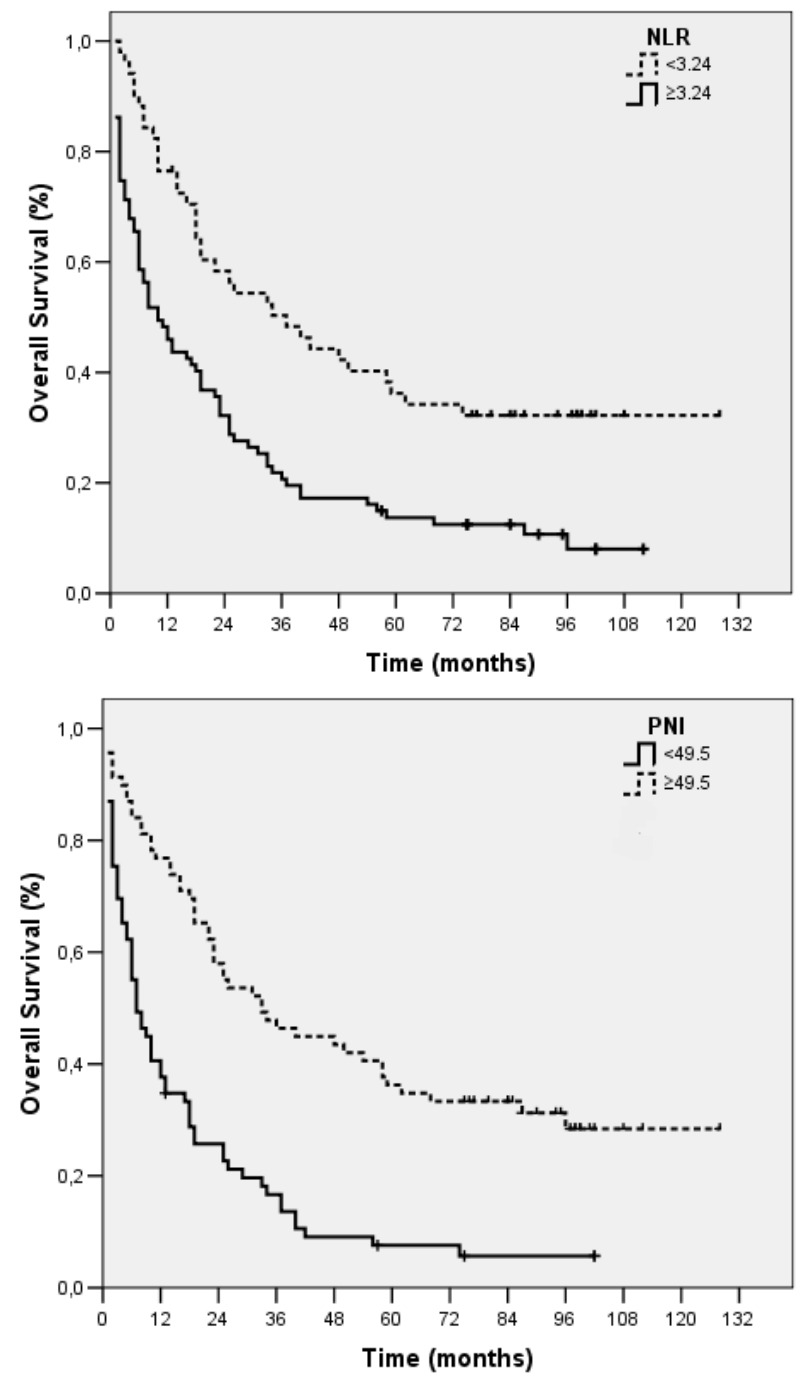

Figure 1. Kaplan-Meier Survival Curves for Overall Survival of All Patients with NLR and PNI Groups

Table 2. Univariate Analysis of Clinical Characteristics on Overall Survival

\begin{tabular}{|c|c|c|c|c|c|c|}
\hline \multirow[t]{2}{*}{ Characteristics } & \multicolumn{2}{|c|}{$\begin{array}{l}\text { All patients } \\
(\mathrm{n}=138)\end{array}$} & \multicolumn{2}{|c|}{$\begin{array}{l}\text { Non-metastatic patients } \\
\qquad(\mathrm{n}=88)\end{array}$} & \multicolumn{2}{|c|}{$\begin{array}{l}\text { Metastatic patients } \\
\qquad(\mathrm{n}=50)\end{array}$} \\
\hline & $\mathrm{HR}^{*}(95 \% \mathrm{CI})$ & $\mathrm{p}$ & $\mathrm{HR} *(95 \% \mathrm{CI})$ & $\mathrm{p}$ & $\mathrm{HR}^{*}(95 \% \mathrm{CI})$ & $\mathrm{p}$ \\
\hline $\begin{array}{l}\text { Age } \\
\qquad \geq 57 v s<57\end{array}$ & $\begin{array}{l}1.38 \\
(0.95-2.00)\end{array}$ & & $\begin{array}{l}1.30 \\
(0.80-2.14)\end{array}$ & & $\begin{array}{l}1.47 \\
(0.82-2.69)\end{array}$ & \\
\hline $\begin{array}{l}\text { Gender } \\
\quad \text { Male } v s \text { Female }\end{array}$ & $\begin{array}{l}1.56 \\
(0.82-3.00)\end{array}$ & 0.18 & $\begin{array}{l}1.93 \\
(0.77-4.83)\end{array}$ & 0.16 & $\begin{array}{l}1.16 \\
(0.45-2.96)\end{array}$ & 0.75 \\
\hline $\begin{array}{l}\text { ECOG } \\
\quad 2-3 v s 0-1\end{array}$ & $\begin{array}{l}1.94 \\
(1.33-2.84)\end{array}$ & 0.001 & $\begin{array}{l}1.87 \\
(1.13-3.09)\end{array}$ & 0.01 & $\begin{array}{l}1.79 \\
(0.99-3.25)\end{array}$ & 0.05 \\
\hline $\begin{array}{l}\text { Stage } \\
\text { IV vs I-III }\end{array}$ & $\begin{array}{l}2.73 \\
(1.85-4.02)\end{array}$ & $<0.0001$ & & & & \\
\hline $\begin{array}{l}\text { Histology } \\
\text { Adenocarcinoma vs others }\end{array}$ & $\begin{array}{l}0.91 \\
(0.62-1.33)\end{array}$ & 0.63 & $\begin{array}{l}1.02 \\
(0.63-1.68)\end{array}$ & 0.92 & $\begin{array}{l}0.88 \\
(0.48-1.59)\end{array}$ & 0.66 \\
\hline $\begin{array}{l}\text { NLR } \\
\quad \geq 3.24 v s<3.24\end{array}$ & $\begin{array}{l}2.17 \\
(1.45-3.26)\end{array}$ & $<0.0001$ & $\begin{array}{l}2.59 \\
(1.52-4.43)\end{array}$ & $<0.0001$ & $\begin{array}{l}1.27 \\
(0.68-2.38)\end{array}$ & 0.45 \\
\hline $\begin{array}{l}\text { PNI } \\
\qquad 49.5 v s<49.5\end{array}$ & $\begin{array}{l}0.37 \\
(0.25-0.55) \\
\end{array}$ & $<0.0001$ & $\begin{array}{l}0.37 \\
(0.22-0.61)\end{array}$ & $<0.0001$ & $\begin{array}{l}0.50 \\
(0.27-0.93) \\
\end{array}$ & 0.03 \\
\hline
\end{tabular}

While median overall survival was 37.0 (95\%CI 17.5$56.5)$ months in the group with low NLR $(<3.24)$, it was calculated as $10.0(95 \% \mathrm{CI} 5.0-15.0)$ months in the group with high NLR $(\geq 3.24)$. The difference between groups was statistically significant. $(\mathrm{p}<0.0001)$. While median overall survival was 7.0 (95\% CI 3.5-10.5) months in the group with low PNI $(<49.5)$ it was calculated as 33.0 (95\%CI 15.5-50.4) months in the group with high PNI $(\geq 49.5)$ and the difference was statistically significant. $(\mathrm{p}<0.0001)$ (Figure 1).

Eighty-eight patients who were non-metastatic at diagnosis (stage I-III) were evaluated; while the median overall survival in the patients with low NLR $(n=37$, 42.0\%) was 59.0 (95\%CI 21.0-97.0) months, the median overall survival in patients with high NLR $(n=51,58.0 \%)$ was 19.0 (95\%CI 10.2-27.7) months. This difference was statistically significant $(\mathrm{p}<0.0001)$. While the median overall survival in the patients with low PNI $(n=38$, $43.2 \%$ ) was 13.0 (95\% CI 5.2-20.8) months, the median overall survival in patients with high PNI $(n=50,56.8 \%)$ was $54.0(95 \% \mathrm{CI} 32.0-75.9)$ months and this is statistically significant $(\mathrm{p}<0.0001)$ (Figure 2$)$.

When evaluated 50 patients with metastasis at diagnosis; the median overall survival of patients with low $\operatorname{NLR}(\mathrm{n}=14,28.0 \%)$ and high NLR $(\mathrm{n}=36,72.0 \%)$ were 10.0 (95\% CI 3.9-16.1) months and 4.0 (95\%CI 1.8-6.2) months, respectively, but the difference was not significant $(\mathrm{p}=0.43)$. While the median overall survival in the patients with low PNI $(n=31,62.0 \%)$ was 5.0 (95\%CI 3.0-7.0) months, the median overall survival in patients with high PNI $(\mathrm{n}=19,38.0 \%)$ was 16.0 (95\%CI 4.6-23.3) months and the difference was significant $(\mathrm{p}=0.02)$ (Figure 2).

In cox regression analysis, age variable was categorized as median age as $<57$ and $\geq 57$. When all patients $(n=138)$ were evaluated, ECOG in univariate analysis ECOG $(\mathrm{p}<0.001)$, stage $(\mathrm{p}<0.0001)$, high NLR $(\mathrm{p}<0.0001)$ and low PNI ( $<<0.0001)$ were determined as poor prognostic factors. When non-metastatic (stage I-III) patients $(n=88)$ were evaluated, ECOG ( $\mathrm{p}<0.01)$, high NLR $(\mathrm{p}<0.0001)$ and low PNI $(\mathrm{p}<0.0001)$ were detected as poor prognostic factors. When the patients who had metastatis at the time 

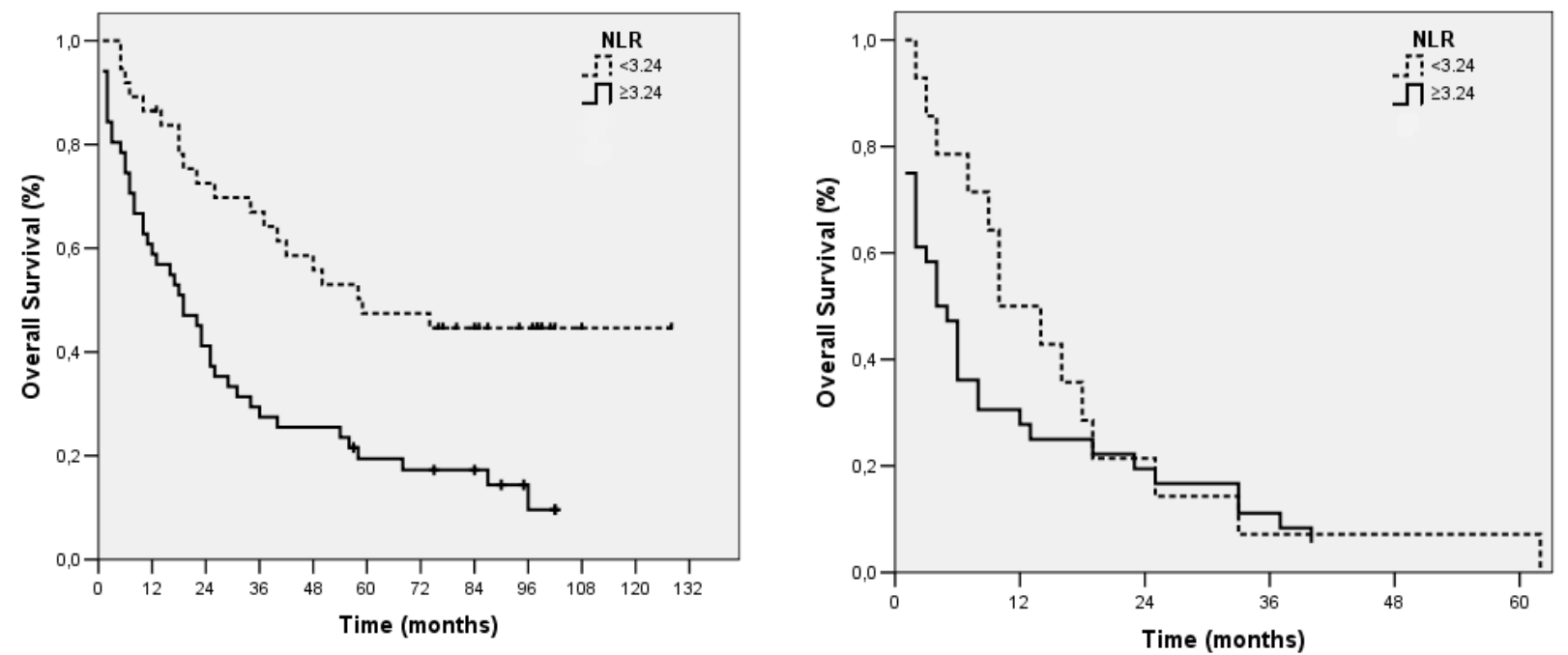

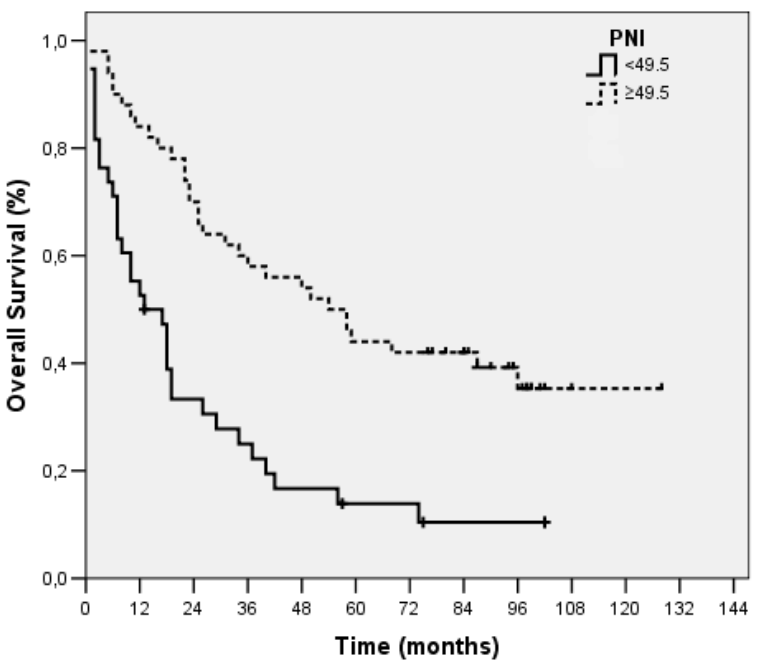

Figure 2. Kaplan-Meier Survival Curves for Overall Survival of Non-metastatic Patients with NLR and PNI Groups

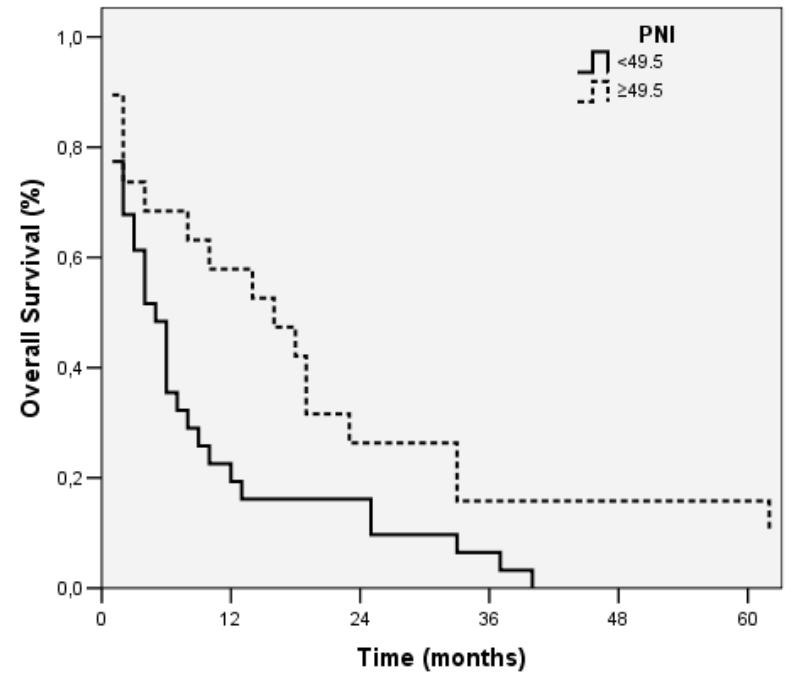

Figure 3. Kaplan-Meier Survival Curves for Overall Survival of Metastatic Patients with NLR and PNI groups

Table 3. Multivariate Analysis of Clinical Characteristics on Overall Survival

\begin{tabular}{|c|c|c|c|c|c|c|}
\hline \multirow[t]{2}{*}{ Characteristics } & \multicolumn{2}{|c|}{$\begin{array}{l}\text { All Patients } \\
(\mathrm{N}=138)\end{array}$} & \multicolumn{2}{|c|}{$\begin{array}{l}\text { Non-Metastatic Patients } \\
\qquad(\mathrm{N}=88)\end{array}$} & \multicolumn{2}{|c|}{$\begin{array}{l}\text { Metastatic Patients } \\
\qquad(\mathrm{N}=50)\end{array}$} \\
\hline & $\mathrm{Hr}^{*}(95 \% \mathrm{Ci})$ & $\mathrm{P}$ & $\mathrm{Hr}^{*}(95 \% \mathrm{Ci})$ & $\mathrm{P}$ & $\mathrm{Hr} *(95 \% \mathrm{Ci})$ & $\mathrm{P}$ \\
\hline $\begin{array}{l}\text { Ecog } \\
\quad 2-3 \text { Vs } 0-1\end{array}$ & $\begin{array}{l}1.35 \\
(0.89-2.04)\end{array}$ & 0.15 & $\begin{array}{l}1.26 \\
(0.73-2.17)\end{array}$ & 0.39 & $\begin{array}{l}1.47 \\
(0.77-2.18)\end{array}$ & 0.25 \\
\hline $\begin{array}{l}\text { Stage } \\
\quad \text { Iv } V s \text { I-Iii }\end{array}$ & $\begin{array}{l}2.34 \\
(1.58-3.48)\end{array}$ & $<0.0001$ & & & & \\
\hline $\begin{array}{l}\mathrm{Nlr} \\
\quad \geq 3.24 \mathrm{Vs}<3.24\end{array}$ & $\begin{array}{l}1.56 \\
(1.02-2.39)\end{array}$ & 0.04 & $\begin{array}{l}2.00 \\
(1.14-3.54)\end{array}$ & 0.02 & $\begin{array}{l}1.08 \\
(0.56-2.08)\end{array}$ & 0.82 \\
\hline $\begin{array}{l}\text { Pni } \\
\qquad \geq 49.5 V s<49.5\end{array}$ & $\begin{array}{l}0.49 \\
(0.32-0.75)\end{array}$ & $<0.001$ & $\begin{array}{l}0.49 \\
(0.28-0.84)\end{array}$ & 0.01 & $\begin{array}{l}0.50 \\
(0.27-0.93)\end{array}$ & 0.03 \\
\hline
\end{tabular}

\section{*HR: Hazard ratio}

of diagnosis $(n=50)$ were evaluated, ECOG $(\mathrm{p}=0.05)$ and low PNI ( $\mathrm{p}=0.03$ ) were poor prognostic factors (Table 2$)$.

Stage, NLR and PNI levels were evaluated as independent risk factors for overall survival for all patients in multivariate analysis $(\mathrm{p}<0.0001, \mathrm{p}=0.04$ and $\mathrm{p}<0.001$, respectively). While mortality rate increased 1.56 fold in patients with high NLR values compared to those with low values, mortality risk was seen to increase 2 fold in patients with low PNI levels compared to the patients those with high PNI levels. Low PNI increased the risk 2 fold in metastatic patients (Table 3).

\section{Discussion}

In our study, high NLR and low PNI values prior to any therapies were shown to be poor prognostic factors independent from other risk factors. When subgroups were evaluated, while both indices had association with overall survival in non-metastatic patients, only low PNI was determined as a prognostic factor in metastatic patients. 
Neutrophils, as well as T and B lymphocytes Prognostic Value of NLR and PNI in Non-Small Cell Lung Cancer are suggested to play a prominent role in the tumor inflammation and immunology. Preclinical studies indicated that neutrophils may act as tumor promoting leukocytes through TGF- $\beta$ induced signal pathway (Yao et al., 2013). Previous clinical data suggested that the biochemical 'cross-talk' between inflammatory cells and the growing neoplastic clone can influence tumour cell survival acting on immune-evasion systems and by enhancing angiogenesis (Bremnes et al., 2011). Tumor progression and metastasis comprise a cascade of steps that involve the interaction between the tumor and the host-derived stromal microenvironment, which includes factors that support angiogenesis and inflammation. (Coussens and Werb, 2002). Inflammation promotes tumour angiogenesis, invasion, and metastasis through recruitment of regulatory $\mathrm{T}$ lympho- cytes and chemokines, activation of interleukin- 6 and tumour necrosis factor alpha, secretion of CRP, induction of neutrophilia, subversion of adaptive immune response, and aberration of response to hormones and chemotherapeutic agents. (Kinoshita et al., 2012). Several mechanisms mediate the association between elevated neutrophil count and progression of cancer such as cancer cells release myeloid growth factors resulting in production of neutrophils and circulating neutrophils secrete various cytokines, including vascular endothelial growth factor (VEGF), tumor necrosis factor- $\alpha$, and interleukins. (Li et al., 2014).

Neutrophil count or lymphocyte count alone may have limited reflection on the inflammation or immune in tumor progression and was not associated with survival prognosis, but together played a strong predictive role in survival (Yao et al., 2013). In NSCLC, chronic inflammation leads to clinical initiation of the cancer (O'callaghan et al., 2010). So, usability of inflammation indices as prognostic parameters has come in the foreground in NSCLC. In literature, limited number of retrospective studies are available in NSCLC despite the presence of studies investigating the influence of NLR on overall survival in various cancer types (Sarraf et al., 2009; Tomita et al., 2011; Cedrés et al., 2012; Yao et al., 2013; Kacan et al., 2014) In a study conducted with early stage NSCLC patients, cut-off value of NLR was determined with ROC analysis and prognosis was reported to be poorer in patients whose cut-off value was above 3.81 (HR:1.1, \%CI: 1.03-1.17, p=0.004) (Sarraf et al., 2009). In the study of Tomita et al., patients were classified according to median NLR (2.5), and preoperative high NLR was detected to be an independent prognostic factor (HR:1.2863 \%CI 1.0462-1.5738, p=0.0173) (Tomita et al). In our study, high NLR value was detected to be a poor prognostic factor in early stage patients. In a study conducted with advanced stage NSCLC patients, cut-off was determined as 2.63 with ROC analysis and mortality risk was reported to be 1.76 fold greater in patients with high values ( $p=0.02)$ (Yao et al., 2013). In another study conducted with advanced stage patients, NLR cut-off value was taken as the same with the studies conducted with cancer types other than NSCLC and NLR $\geq 5$ was shown to be an independent prognostic factor (HR 1.595, CI:1.1-0.2.1\%, p=0.015) (Cedrés et al., 2012). In our

study, median overall survival was 6 months shorter in patients with high NLR values in metastatic patient group however the difference was not statistically significant. The potential reason for this was our small number of patients in subgroup analysis. Different NLR cut-off values were investigated in the recent study conducted with the patients in all stages of NSCLC and NLR $\geq 5$ was detected as an independent risk factor in multivariate analysis (HR: 1.7, $\mathrm{p}=0.017$ ).

There are several studies evaluating NLR and different inflammation indices (Platelet/Lymphocyte Rates, serum LDH, albumin) beside the studies evaluating only NLR (Kaya et al., 2013; Unal et al., 2013; Yildirim et al., 2013; Pinato et al., 2014). Elevated NLR was interpreted as an independent prognostic index for overall survival. Among them, only the study of Pinato et al. is a prospcetive study consisting 220 NSCLC patients (Pinato et al., 2014). In this study, NLR, Platelet/Lymphocyte Rates (PLR) and Glasgow Prognostic Score (mGPS) were evaluated together as inflammation-based scores. The cut-off NLR value was used in the studies conducted with cancer patients other than lung cancer. In multivariate analysis of the study, NLR $>5$ was shown to be a predictive value for short OS (HR:2.3, CI 1.0-5.0\%, p=0.04).

Previous studies have suggested that albumin and lymphocyte levels have a close relationship with the presence of an infammatory response in cancer patients (Feng and Chen, 2014). Hypoalbuminemia is often observed in advanced cancer patients, and is usually regarded as an index of malnutrition and cachexia ( $\mathrm{Li}$ et al., 2014). However there is increasing evidence that the presence of cancer cachexia, partly reflected by a reduction in albumin, is driven by a sustained inflammatory response, either from the tumour itself or as a host reaction (Pinato et al., 2012). Therefore, although initially thought of purely as a reflection of the nutritional status of a patient, it is likely, given its prognostic association, that PNI is a reflection of systemic inflammation (Mohri et al., 2013). Furthermore, the presence of an inflammatory response is proposed to be pathogenic in the development of cancer-associated malnutrition, resulting in poor performance status and increased mortality in patients with cancer (Kinoshita et al., 2012). No studies are available investigating whether PNI is a prognostic factor for overall survival in NSCLC pateints. The strength of our study; to the best of our knowledge, our study is the first study on this issue. In the studies investigating PNI in gastrointestinal cancers, cut-off value was either mean/ median values (Nozoe et al., 2002; Mohri et al., 2013) or 45 was accepted as cut-off value as in previous studies (Pinato et al., 2012; Wang et al., 2012). Median PNI value was used in our study. There is a study investigating the prognostic importance of PNI in malignant pleural mesothelioma (Yao et al., 2013). Patients were classified according to mean PNI value (44.6) in that study. In this study reported that patients with lower PNIs $(\mathrm{PNI}<44.6)$ had greater risk of death than those with higher PNIs (PNI $\geq 44.6$; HR: 2.290 ; 95 \%CI: 1.415-3.706; $\mathrm{p}=0.001$ ).

Our study evaluates NLR and PNI together as systemic inflammatory reponse markers in NSCLC however its being retrospective so many data points may not be 
accurately recorded and small number of patients are the limitations of our study, therefore prospective studies conducted with larger number of patients are required for verifying our results.

\section{References}

Balkwill F, Mantovani A (2001). Inflammation and cancer: back to virchow? Lancet, 357, 539-45.

Bremnes RM, Al-Shibli K, Donnem T, et al (2011). The role of tumor-infiltrating immune cells and chronic inflammation at the tumor site on cancer development, progression and prognosis: emphasis on non-small cell lung cancer. J Thorac Oncol, 6, 824-33.

Cedrés S, Torrejon D, Martínez A, et al (2012). Neutrophil to lymphocyte ratio (NLR) as an indicator of poor prognosis in stage IV non-small cell lung cancer. Clin Transl Oncol, 14, 864-9.

Coussens LM, Werb Z (2002). Inflammation and cancer. Nature, 420, 860-7.

Crinò L, Weder W, van Meerbeeck J, Felip E (2010). ESMO Guidelines Working Group: Early stage and locally advanced (non-metastatic) non-small-cell lung cancer: ESMO clinical practice guidelines for diagnosis, treatment and follow-up. Ann Oncol, 21, 103-15.

Feng JF, Chen QX (2014). Significance of the prognostic nutritional index in patients with esophageal squamous cell carcinoma. Ther Clin Risk Manag, 10, 1-7.

Kacan T, Babacan NA, Seker M, et al (2014). Could the neutrophil to lymphocyte ratio be a poor prognostic factor for non small cell lung cancers? Asian Pac J Cancer Prev, 15, 2089-94.

Kaya V, Yildirim M, Demirpence O, Yıldız M, Yalcin A (2013). Prognostic significance of basic laboratory methods in nonsmall-cell-lung cancer. Asian PacJ Cancer Prev, 14, 5473-6.

Kinoshita A, Onoda H, Imai N, et al (2012). Comparison of the prognostic volue of inflammation-based prognostic scores in patients with hepatocellularcarcinoma. Br J Cancer, 107, 988-93.

Kwon HC, Kim SH, Oh SY, et al (2012). Clinical significance of preoperative neutrophil-lymphocyte versus plateletlymphocyte ratio in patients with operable colorectal cancer. Biomarkers, 17, 216-22.

Li QQ, Lu ZH, Yang L, et al (2014). Neutrophil count and the inflammation-based glasgow prognostic score predict survival in patients with advanced gastric cancer receiving first-line chemotherapy. Asian Pac J Cancer Prev, 15, 945-50.

Migita K, Takayama T, Saeki K,et al (2013). The prognostic nutritional index predicts long-term outcomes of gastric cancer patients independent of tumorstage. Ann Surg Oncol, 20, 2647-54.

Mohri Y, Inoue Y, Tanaka K, et al (2013). Prognostic nutritional index predicts postoperative outcome in colorectal cancer. World J Surg, 37, 2688-92.

Nozoe T, Kimura Y, Ishida M, et al (2002). Correlation of pre-operative nutritional condition with post-operative complications in surgical treatment for oesophageal carcinoma. Eur J Surg Oncol, 28, 396-400.

O'callaghan Ds, O'donnell D, O'connell F, O'byrne Kj (2010). The role of inflammation in the pathogenesis of non-small cell lung cancer. J Thorac Oncol, 5, 2024-36.

Onodera T, Goseki N, Kosaki G (1984). Prognostic nutritional index in gastrointestinal surgery of malnourished cancer patients. Nihon Geka Gakkai Zasshi, 85, 1001-5.

Pinato DJ, North BV, Sharma R (2012). A novel, externally validated inflammation based prognostic algorithm in hepatocellular carcinoma: the prognostic nutritional index (PNI). Br J Cancer, 106, 1439-45.

Pinato DJ, Shiner RJ, Seckl MJ, et al (2014). Prognostic performance of inflammation-based prognostic indices in primary operable non-small cell lung cancer. Br J Cancer, 110, 1930-35.

Sarraf KM, Belcher E, Raevsky E, et al (2009). Neutrophil/ lymphocyte ratio and its association with survival after complete resection in non-small cell lung cancer. $J$ Thorac Cardiovasc Surg, 137, 425-8.

Siegel R, Naishadham D, Jemal A (2013). Cancer statistics, 2013. CA Cancer J Clin, 63, 11-30.

Sun K, Chen S, Xu J, Li G, He Y (2014). The prognostic significance of the prognostic nutritional index in cancer: a systematic review and meta-analysis. J Cancer Res Clin Oncol, 14, 1537-49

Tomita M, Shimizu T, Ayabe T, Yonei A, Onitsuka T (2011). Preoperative neutrophil to lymphocyte ratio as a prognostic predictor after cerative resection for non-small celllung cancer. Anticancer Res, 31, 2995-8.

Unal D, Eroglu C, Kurtul N, Oguz A, Tasdemir A (2013). Are neutrophil/lymphocyte and platelet/lymphocyte rates in patients with non-small cell lung cancer associated with treatment response and prognosis? Asian Pac J Cancer Prev, 14, 5237-42.

Wang DS, Luo HY, Qiu MZ, et al (2012). Comparison of the prognostic values of various inflammation based factors in patients with pancreatic cancer. Med Oncol, 29, 3092-100.

Xu AM, Huang L, Zhu L, Wei ZJ (2014). Significance of peripheral neutrophil-lymphocyte ratio among gastric cancer patients and construction of a treatment-predictive model: a study based on 1131 cases. Am J Cancer Res, 4, 189-95.

Yao Y, Yuan D, Liu H, Gu X, Song Y (2013). Pretreatment neutrophil to lymphocyte ratio is associated with response to therapy and prognosis of advanced non-small cell lung cancer patients treated with first-line platinum-based chemotherapy. Cancer Immunol Immunother, 62, 471-9.

Yao ZH, Tian GY, Wan YY, et al (2013). Prognostic nutritional index predicts outcomes of malignant pleural mesothelioma. J Cancer Res Clin Oncol, 139, 2117-23.

Yildirim M, Yildiz M, Duman E, Goktas S, Kaya V (2013). Prognostic importance of the nutritional status and systemic inflammatory response in non-small cell lung cancer. J Buon, 18, 728-32. 